\title{
Isotope Fractionation of Water during Evaporation without Condensation
}

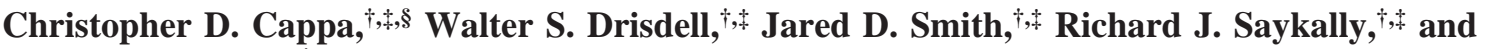 \\ Ronald C. Cohen*, \\ Department of Chemistry, University of California, Berkeley, California 94720-1460, and Lawrence Berkeley \\ National Laboratory, Berkeley, California 94720
}

Received: July 15, 2005; In Final Form: October 19, 2005

\begin{abstract}
The microscopic events engendering liquid water evaporation have received much attention over the last century, but remain incompletely understood. We present measurements of isotope fractionation occurring during free molecular evaporation from liquid microjets and show that the isotope ratios of evaporating molecules exhibit dramatic differences from equilibrium vapor values, strong variations with the solution deuterium mole fraction, and a clear temperature dependence. These results indicate the existence of an energetic barrier to evaporation and that the evaporation coefficient of water is less than unity. These new insights into water evaporation promise to advance our understanding of the processes that control the formation and lifetime of clouds in the atmosphere.
\end{abstract}

\section{Introduction}

Over the last century, numerous experiments have been conducted to elucidate the mechanisms that control evaporation, condensation, and trace gas uptake on the surfaces of water and other liquids. The macroscopic processes of evaporation and condensation are governed by the microscopic processes that transport individual water molecules across the interface from the bulk liquid to the vapor, and vice versa. Besides being of fundamental interest, these basic processes are important in atmospheric phenomena, e.g., in controlling the formation and persistence of clouds and in changing the composition, reactivity, and radiative properties of aerosols. ${ }^{1,2}$ The microscopic mechanism of evaporation can be described as a multistep process wherein a liquid-phase molecule diffuses to the interfacial region and, after a characteristic residence time, either evaporates or returns to the bulk liquid. Few experiments have probed these individual molecular processes directly. Due to the high volatility of many important liquids, evaporating and condensing molecules undergo many collisions in a gaseous layer near the surface, and bulk samples of volatile liquids are always simultaneously undergoing evaporation and condensation, thereby greatly complicating direct study of either process in isolation. Here, we report on experiments in which liquid microjets are used to enable studies of evaporation from liquid water as a unidirectional process.

Molecular beam scattering experiments on very low vapor pressure liquids (e.g., glycerol, squaline, and concentrated $\mathrm{H}_{2}$ $\mathrm{SO}_{4}$ ) have contributed much to our understanding of the fundamentals of uptake and condensation and have provided new insights into the microscopic events involved in condensation. ${ }^{3}$ Correspondingly, detailed studies on the evaporation of high vapor pressure liquids (in particular, water) as a unique process, separate from condensation, are far rarer, ${ }^{4,5}$ although a significant amount of literature exists on liquid water evaporation

\footnotetext{
University of California, Berkeley.

$\doteqdot$ Lawrence Berkeley National Laboratory.

$\S$ Present address: NOAA Earth System Research Laboratory, Boulder, Colorado 80305.
}

as a net process, ${ }^{6,7}$ and some studies of uptake have been interpreted has having implications for evaporation. ${ }^{8}$

Many of the net evaporation studies have focused on determining the evaporation coefficient $\left(\gamma_{\mathrm{e}}\right)$ for water. The term $\gamma_{\mathrm{e}}$ is defined as the ratio of the observed evaporation rate to the theoretical maximum rate $\left(J_{\mathrm{e}, \max }\right)$ given by the HertzKnudsen equation, ${ }^{9}$

$$
J_{\mathrm{e}, \max }=\frac{p_{\mathrm{sat}}}{\sqrt{2 \pi m k T}}
$$

where $p_{\text {sat }}$ is the saturation vapor pressure, $m$ is mass, $k$ is the Boltzmann constant, and $T$ is temperature. Accordingly,

$$
J_{\mathrm{e}, \mathrm{obs}}=\gamma_{\mathrm{e}} J_{\mathrm{e}, \max }
$$

At equilibrium, the net evaporative flux equals the net condensation flux $\left(J_{\text {e,eqm }}=J_{\text {c,eqm }}\right)$. However, it is not a requirement that these microscopic rates of transport across the liquid water surface proceed at the maximum rate, namely with $\gamma_{\mathrm{e}}=1$.

To date, there has been no definitive experimental determination of $\gamma_{\mathrm{e}}$ for water. Values of $\gamma_{\mathrm{e}}$ spanning 3 orders of magnitude have been reported, with the most recent measurements indicating that $\gamma_{\mathrm{e}}>0.1 .^{6,7}$ It has often been concluded that $\gamma_{\mathrm{e}}=1$ even when smaller values were experimentally observed. ${ }^{10,11}$ The major sources of uncertainty in the determination of $\gamma_{\mathrm{e}}$ appear to be (i) surface contamination, (ii) the ability to specify the surface temperature accurately, and (iii) the ability to accurately account for recondensation. Although many authors focus on the first two points, this third point is particularly important, given that nearly all previous studies on the evaporation of liquid water were performed under conditions wherein condensation was significant. Moreover, all previous attempts to determine $\gamma_{\mathrm{e}}$ for liquid water have measured absolute evaporation rates and then related these absolute rates to $J_{\mathrm{e}, \max }$. Because evaporation and condensation are intimately coupled processes, studies of water condensation are also relevant. However, as with the evaporation coefficient, there is no agreement in the literature as to the absolute magnitude of the mass accommodation (MA), or uptake, coefficient of water onto 
(a)

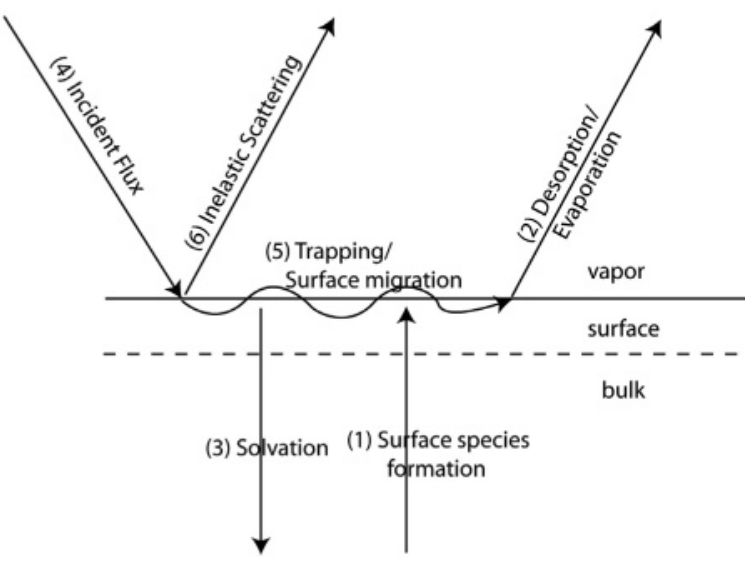

(b)

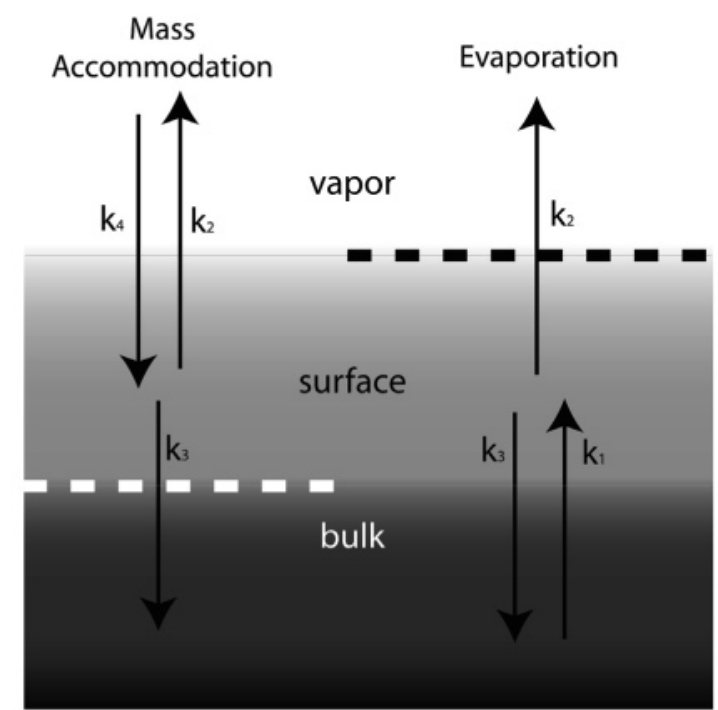

Figure 1. (a) Schematic of evaporation and mass accommodation (uptake). For evaporation, molecules from the bulk liquid must first (1) move from the bulk liquid to the surface and form a surface species and then (2) evaporate before they are (3) returned to the bulk liquid. Gas-phase molecules (4) incident on the liquid surface can (5) thermally accommodate with the liquid surface or (6) scatter inelastically. Molecules that are thermally accommodated can then either (2) desorb or (3) be accommodated into the bulk liquid. (b) Evaporation (right) and mass accommodation (left) models of mass transfer at the liquid surface. For condensation, the dividing surface for mass transfer is located between the surface layer and the bulk liquid, illustrated by the dashed white line. For evaporation, the dividing surface is located between the surface layer and the vapor, illustrated by the dashed black line.

water. ${ }^{7}$ Even the two most recent experiments in which the mass accommodation coefficient was measured yielded conflicting values, i.e., $\mathrm{MA}=0.3^{12}$ vs $\mathrm{MA}=1 .{ }^{13}$

The evaporation and mass accommodation associated with liquids are often considered to be multistep processes (Figure 1a). Evaporation first involves the transfer of a molecule from the bulk liquid to the liquid surface (process 1). This surface species can then either evaporate (process 2) or return to the bulk liquid (process 3). Mass accommodation in nonreacting systems consists first of thermal accommodation of incident molecules with the liquid surface (process 4), and then, this newly formed surface species either enters the liquid (process 3 ), travels along the surface (process 5), or desorbs from the surface (process 2) before it has a chance to be captured into the bulk. ${ }^{8,14,15}$ In any experiment that probes evaporation or mass accommodation, it is important to clearly specify which of the

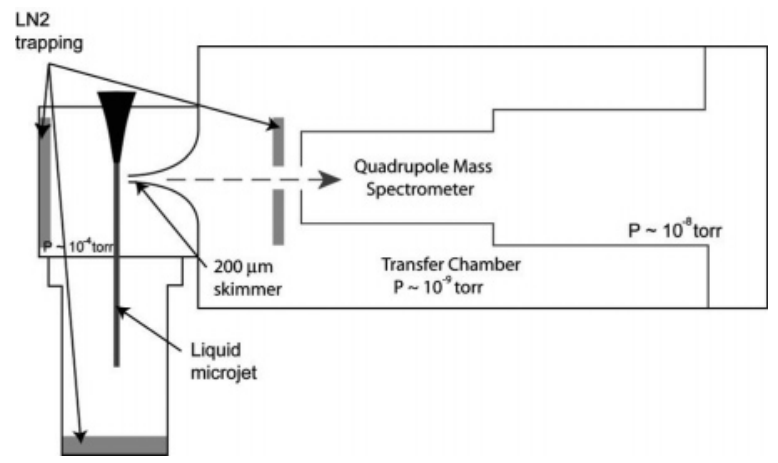

Figure 2. Schematic of the experimental setup. Evaporate from the liquid jet is sampled through a $200-\mu \mathrm{m}$ diameter parabolic skimmer into the transfer chamber and then into the quadrupole mass spectrometer. The evaporate is measured via electron impact ionization where the electron kinetic energy is $17 \mathrm{eV}$, allowing for specific detection of the parent ions $\left(\mathrm{H}_{2} \mathrm{O}^{+}, \mathrm{HDO}^{+}\right.$, and $\left.\mathrm{D}_{2} \mathrm{O}^{+}\right)$.

individual processes represented in Figure 1a are under consideration because combinations of steps can produce distinctly different constants representing aggregate processes, e.g., $\gamma_{\mathrm{e}}$ or MA, even though the apparent definitions are equivalent (cf. eq 2). For example, the differences in the individual steps involved in the overall evaporation and mass accommodation processes are shown in Figure 1b and will be discussed in detail later.

In the experiments on evaporation described here, we make use of small liquid microjets $\left(r_{\text {jet }}<3.5 \mu \mathrm{m}\right)$ to create a physical situation wherein essentially collisionless evaporation occurs from high vapor pressure liquids (i.e., water) with negligible recondensation. Isotopic mixtures of liquid water (rather than pure $\mathrm{H}_{2} \mathrm{O}$ ) are utilized, allowing the consideration of evaporation primarily as a relative process rather than as an absolute process. Specifially, isotope fractionation factors associated with free evaporation $\left(\alpha_{\text {evap }}\right)$ have been measured as a function of the isotopic composition and temperature of the liquid. (Unfortunately, $\alpha$ has been traditionally used to represent both isotope fractionation factors and the mass accommodation coefficient. For clarity, we use $\alpha$ to describe isotope fractionation and MA to represent the mass accommodation coefficient.) The observed values of $\alpha_{\text {evap }}$ exhibit strong deviations from equilibrium fractionation factors $\left(\alpha_{\text {eqm }}\right)$ and a clear dependence on the isotopic composition of the liquid, demonstrating that a significant energetic barrier to the free evaporation of water exists and that the evaporation coefficient for liquid water is, therefore, less than unity.

\section{Materials and Methods}

2.1. General Experimental Design. The evaporation from small liquid jets is nearly collisionless, thereby allowing the determination of properties associated with free molecular evaporation. Also, the surface is continually renewed, thereby minimizing the possibility of contamination by adsorption to the surface. The isotopic composition of the evaporating molecules from a liquid jet was determined using a quadrupole mass spectrometer operated in electron impact mode. Our experimental setup consists of a three stage, differentially pumped chamber system in which evaporate from the liquid jet is sampled into the mass spectrometer for the determination of isotope ratios (Figure 2).

In the first stage, a liquid microjet (radius $=2-15 \mu \mathrm{m}$ ) is allowed to evaporate into a high vacuum chamber maintained at a pressure of $\sim 10^{-4}$ Torr by a $150 \mathrm{~L} / \mathrm{s}$ turbomolecular pump. At this pressure, the mean free path is $\sim 0.8 \mathrm{~m}, \sim 10$ times larger 
than the width of the evaporation chamber. The jet is collected into a liquid nitrogen (LN2) cooled trap after traveling $\sim 3 \mathrm{~cm}$ in the evaporation chamber. Additional LN2 trapping is used around the liquid jet in the evaporation chamber in order to maintain a high vacuum in the presence of the rapidly evaporating liquid. The evaporating molecules are sampled through a $200-\mu \mathrm{m}$ diameter parabolic skimmer into the second "transfer" chamber. During sampling, the liquid jet is located within $500 \mu \mathrm{m}$ of the skimmer entrance. A LN2 cooled plate is located directly opposite the skimmer entrance in the liquid jet chamber to further reduce the background signal. The liquid jet assembly is mounted on a three-way manipulator to allow for in vacuo control of the liquid jet position with respect to the skimmer entrance. The pressure in the transfer chamber is $<3 \times 10^{-8}$ Torr under normal operating conditions, dependent upon the position of the liquid jet with respect to the skimmer. A LN2 cooled copper plate with a 3-mm aperture is located directly inline between the skimmer and the entrance to the third chamber, which houses the quadrupole mass spectrometer. This plate acts as a cold trap, providing significant reduction in background signals. Pressures in the quadrupole chamber are maintained at $<2 \times 10^{-8}$ Torr.

The liquid jets are produced by pressurizing the isotopic solutions behind fused silica capillary nozzles using a high performance liquid chromatograph (HPLC) pump. Liquid jet nozzles are produced by pulling standard $100 \mu \mathrm{m}$ i.d. (360 $\mu \mathrm{m}$ o.d.) fused silica capillaries to the desired final nozzle diameter using a commercial $\mathrm{CO}_{2}$ laser micropipet puller.

All isotopic solutions were prepared gravimetrically from high purity $\mathrm{H}_{2} \mathrm{O}\left(18 \mathrm{M} \Omega\right.$, Millipore) and $\mathrm{D}_{2} \mathrm{O}(99.9 \% \mathrm{D}$, Cambridge Isotope Labs).

The use of extensive LN2 trapping served to significantly reduce background signals; however, it was still necessary to explicitly subtract the background contribution to the total signal prior to calculating the isotope ratios. The background contribution was determined by monitoring the $\mathrm{X}_{2} \mathrm{O}^{+}(\mathrm{X}=\mathrm{H}$ or $\mathrm{D})$ signals when the liquid jet was positioned behind, or "off", the skimmer entrance. The $\mathrm{X}_{2} \mathrm{O}^{+}$values are taken as the difference between that measured "on" and "off"; i.e., $\mathrm{X}_{2} \mathrm{O}^{+}=\mathrm{X}_{2} \mathrm{O}^{+}$on $\mathrm{X}_{2} \mathrm{O}^{+}{ }_{\text {off. }}$. All isotope ratios presented were determined as these background-corrected values. The background correction was typically $5-10 \%$ of the total signals. A slightly larger background correction was often necessary for $\mathrm{H}_{2} \mathrm{O}$ than for HDO or $\mathrm{D}_{2} \mathrm{O}$ as a result of contributions from ambient water to the measured signal. In a typical experiment, the $\mathrm{X}_{2} \mathrm{O}^{+}$values are monitored for $5 \mathrm{~min}$ in the on position and $5 \mathrm{~min}$ in the off position for $\sim 2 \mathrm{~h}$ total ( $\sim 10$ measurements total). Only the last minute of each 5-min measurement period is used in the determination of the isotope ratios. The reported errors are taken as the standard deviations calculated from the $\sim 10$ measurements at each isotopic composition. Upon initial startup, the observed background levels are out of proportion to the composition of the liquid jet, with relatively high $\mathrm{H}_{2} \mathrm{O}^{+}$signals. The background levels drop rapidly at first but after $\sim 2 \mathrm{~h}$ of warm-up time are very constant and representative of the liquid jet composition. All data is collected after this initial warm-up period. The temperature dependence of the isotope ratios in the evaporate was determined by measuring the $\mathrm{X}_{2} \mathrm{O}^{+}$signals at different positions along the length of the liquid jet, which cools rapidly by evaporation.

2.2. Electron Impact Ionization. The use of electron impact ionization to ionize water molecules can lead to extensive fragmentation of the parent molecule if the kinetic energy of the electrons is high. However, it is possible to tune the electron energy to just a few electronvolts above the ionization threshold such that only the parent ions are formed (i.e., $\mathrm{X}_{2} \mathrm{O}^{+}$). ${ }^{16}$ The electron kinetic energy used in these experiments is $17 \mathrm{eV}$, which is below the fragmentation threshold. Additionally, the absolute cross sections for $\mathrm{H}_{2} \mathrm{O}$ and $\mathrm{D}_{2} \mathrm{O}$ ionization by electron impact at $17 \mathrm{eV}$ are identical. ${ }^{16}$ Thus, the absolute isotope ratios of the evaporate can be determined by direct measurement of the $\mathrm{X}_{2} \mathrm{O}^{+}$currents. The observed $\mathrm{X}_{2} \mathrm{O}^{+}$currents are proportional to the number of molecules evaporating from the liquid jet, and therefore, the observed isotope ratios are characteristic of the absolute isotope ratios associated with freely evaporating molecules.

2.3. Evaporation from a Liquid Jet. Nearly all previous studies on the evaporation and condensation of water suffer from the complication of the recondensation of the evaporating molecules (or the evaporation of the condensing molecules), making it difficult, if not impossible, to directly probe evaporation as a fundamental, molecular-scale process. ${ }^{6,7}$ The conditions for molecular evaporation are realized for a liquid jet when the Knudsen condition is satisfied, namely when the mean free path $(\lambda)$ of the evaporating molecules is larger than the diameter of the liquid jet $\left(d_{\text {jet }}\right)$. For water, the equilibrium vapor pressure at $295 \mathrm{~K}$ is 19.7 Torr, corresponding to $\lambda \sim 5.2 \mu \mathrm{m}$. That is, on average, the distance between molecules undergoing simultaneous evaporation is $5.2 \mu \mathrm{m}$. Thus, when $d_{\text {jet }}<5 \mu \mathrm{m}$, we expect evaporating water molecules to experience very few collisions with other evaporating molecules on average. Additionally, the vast majority of collisions that do occur will not lead to reflection of an evaporating molecule back into the liquid but will simply change the trajectory and speed of the evaporating molecule, and thus, the Knudsen condition is significantly relaxed.

The vapor density of water molecules around the evaporating liquid jet will fall off rapidly with distance from the center of the liquid jet $(r)$ approximately as ${ }^{17}$

$$
n(r) \approx n\left(r_{\text {jet }}\right) \frac{r_{\text {jet }}}{r} \frac{L}{\sqrt{r^{2}+L^{2}}}
$$

where $n\left(r_{\text {jet }}\right)$ is the water vapor density just above the liquid jet surface, $L$ is the liquid jet length exposed to the detector, and $r_{\text {jet }}$ is the liquid jet radius. The total number of collisions experienced by an evaporating molecule as it travels away from the liquid jet is related to the mean free path at every point along the trajectory away from the liquid jet, where $\lambda$ is given by

$$
\lambda(r)=\left(2^{1 / 2} \pi \sigma_{\mathrm{col}}^{2} n(r)\right)^{-1}=\frac{k T}{2^{1 / 2} \pi \sigma_{\mathrm{col}}^{2} p(r)}
$$

where $\sigma_{\mathrm{col}}$ is the collision diameter of a water molecule $\left(\sigma_{\mathrm{col}}=\right.$ $\left.2.6 \times 10^{-10} \mathrm{~m}\right),{ }^{18} k$ is Boltzmann's constant, and $T$ is temperature in kelvin. The term $p(r)$ is the pressure at a distance $r$ from the center of the jet. The average number of collisions experienced by an evaporating molecule is then ${ }^{19}$

$$
N_{\mathrm{col}}(r, T)=\int_{r_{0}}^{r} \frac{1}{\lambda(r)} \mathrm{d} r \approx \frac{\sqrt{2} \pi \sigma_{\mathrm{col}}^{2} p_{\mathrm{sat}}(T) r_{\mathrm{jet}} L}{k T} \int_{r_{0}}^{r} \frac{1}{r} \frac{\mathrm{d} r}{\sqrt{r^{2}+L^{2}}}
$$

where $p_{\text {sat }}$ is the saturation vapor pressure of water for a given temperature. Note that eq 5 provides an upper limit for $N_{\text {col }}$ because it is assumed that it is appropriate to use $p_{\text {sat }}$ to determine the vapor density at the liquid jet surface, i.e., that 


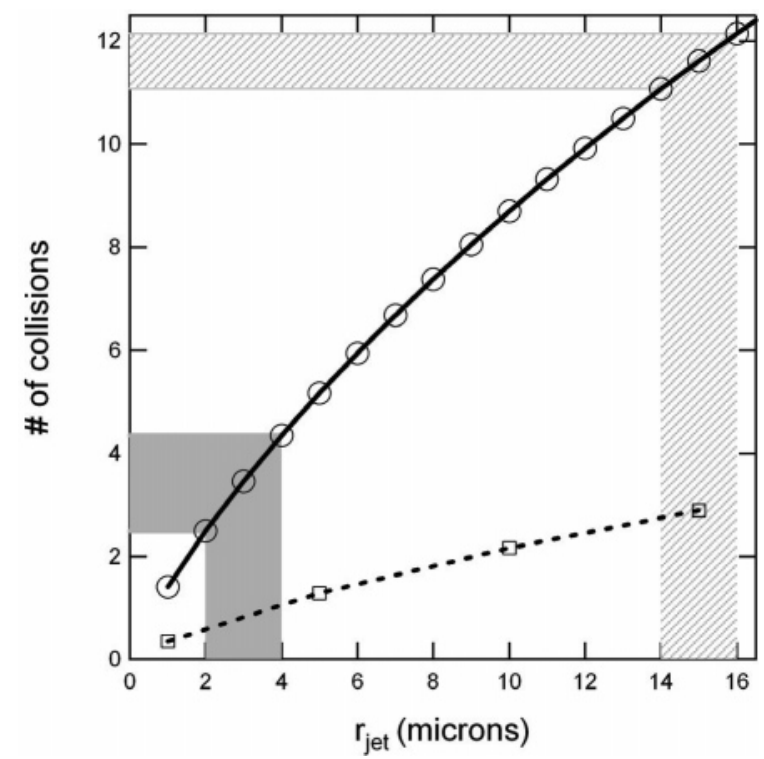

Figure 3. Average number of collisions experienced by a water molecule after evaporating from a liquid jet surface at $295 \mathrm{~K}$ (solid line) or at $273 \mathrm{~K}$ (dashed line) as a function of jet radius $\left(r_{\mathrm{jet}}\right)$. For the experiments performed here, $r_{\mathrm{jet}}<4 \mu \mathrm{m}$ and, more typically, is around $2 \mu \mathrm{m}$ (solid region). A few experiments were performed using larger size jets (crosshatched region).

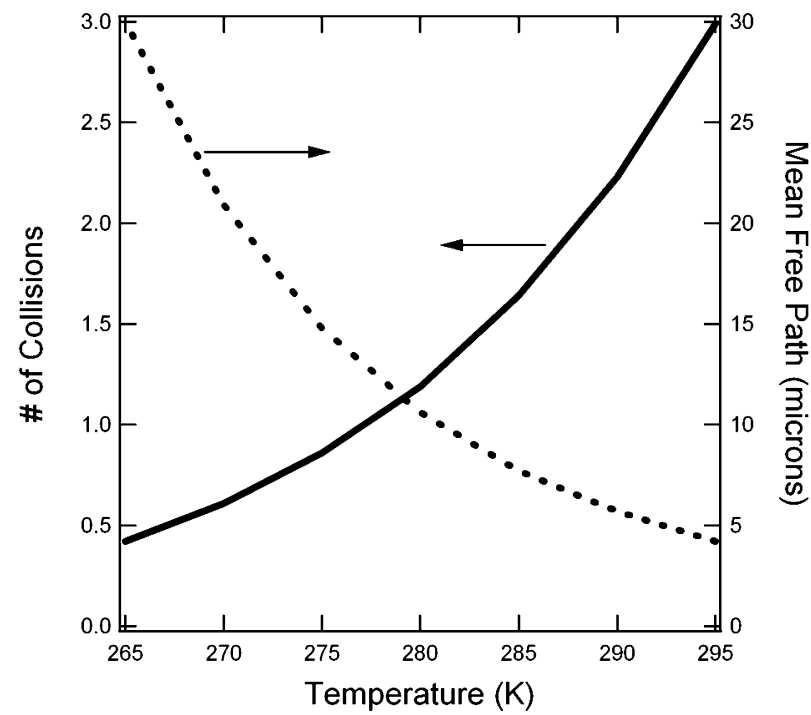

Figure 4. Average number of collisions (solid line) experienced by a molecule evaporating from a $2.5-\mu \mathrm{m}$ radius liquid jet as a function of the jet temperature. Also shown is the mean free path of water assuming saturated vapor (dashed line).

$\gamma_{\mathrm{e}}=1$. The calculated values of $N_{\text {col }}$ (with $L=200 \mu \mathrm{m}$, the diameter of the skimmer) at two temperatures (295 and $273 \mathrm{~K}$ ) as a function of the jet radius are shown in Figure 3. When $r_{\text {jet }}$ $<3 \mu \mathrm{m}$ (typical of the experiments performed herein), $N_{\mathrm{col}}<$ 3.5 , increasing to $N_{\mathrm{col}}=12$ for $r_{\text {jet }}=15 \mu \mathrm{m}$ at $295 \mathrm{~K}$. We have also calculated the average number of collisions for $r_{\text {jet }}=2.5$ $\mu \mathrm{m}$ as a function of temperature (Figure 4 ). As the temperature decreases, the number of collisions decreases, falling to $<1$ collision for water at the triple point $(273 \mathrm{~K})$. Consistent with these calculations, Faubel and co-workers observed that the velocity distribution of molecules evaporating from small liquid jets $\left(r_{\text {jet }}<5 \mu \mathrm{m}\right)$ was indicative of free evaporation, while the velocity distribution from larger liquid jets $\left(r_{\text {jet }}=25 \mu \mathrm{m}\right)$ was significantly narrower due to collisional cooling upon expansion from the vapor layer over the larger jets. ${ }^{4,5}$ From this, we conclude that recondensation of evaporating molecules does not significantly influence our results.

2.4. Evaporative Cooling of Liquid Jets. As a liquid jet evaporates in a vacuum, the evaporating molecules transport heat away from the liquid jet. The cooling rate as the jet travels in a vacuum is dependent upon the evaporative flux away from the jet surface, $J_{\mathrm{e}}$ (molecules $\left./\left(\mathrm{m}^{2} \mathrm{~s}\right)\right)$, the enthalpy of vaporization, $\Delta H_{\text {vap }}(\mathrm{J} / \mathrm{mol})$, and the heat capacity of the liquid, $C_{\mathrm{P}}(\mathrm{J} /$ $(\mathrm{mol} \mathrm{K}))$. The temperature profile along the liquid jet as it evaporates can be modeled $^{5}$ according to

$$
\mathrm{d} T=-\Gamma \frac{\Delta H_{\mathrm{vap}}}{C_{\mathrm{p}}}
$$

where $\mathrm{d} T$ is an infinitesimal temperature decrease due to evaporation events. $\Gamma$ is the ratio of the number of molecules that have evaporated to the number that remain in the jet. Accordingly, for a cylinder

$$
\Gamma=\frac{J_{\mathrm{e}}\left[2 \pi r_{\text {jet }} \mathrm{d} z\right]}{\rho_{\text {liq }}\left[\pi r_{\text {jet }}^{2} \mathrm{~d} z\right]} \mathrm{d} t=2 \frac{J_{\mathrm{e}}}{\rho_{\text {liq }} r_{\text {jet }}} \mathrm{d} t
$$

where $\rho_{\text {liq }}$ is the density of the liquid and $\mathrm{d} z$ is an infinitesimal ring around the circumference of the liquid jet. Combining eqs 6 and 7 gives

$$
\frac{\mathrm{d} T}{\mathrm{~d} t}=-2 \frac{J_{\mathrm{e}}}{\rho_{\text {liq }} r_{\text {jet }}} \frac{\Delta H_{\mathrm{vap}}}{C_{\mathrm{P}}}
$$

or, converting from time to distance along the jet,

$$
\frac{\mathrm{d} T}{\mathrm{~d} z}=-2 \frac{J_{\mathrm{e}}}{\rho_{\text {liq }} r_{\text {jet }}} \frac{\Delta H_{\mathrm{vap}}}{C_{\mathrm{P}}} v_{\text {jet }}=-2 \frac{\phi_{\mathrm{e}} p_{\mathrm{sat}}}{\sqrt{2 \pi m k T}} \frac{\Delta H_{\mathrm{vap}}}{\rho_{\text {liq }} r_{\text {jet }} C_{\mathrm{P}}} v_{\text {jet }}
$$

where $m$ is the mass of the evaporating molecules and $v_{\text {jet }}$ is the liquid jet velocity. $\phi_{\mathrm{e}}$ is an experimentally determined parameter that describes the cooling of liquid microjets due to evaporation in a vacuum. ${ }^{20}$ Given knowledge of the initial jet temperature, eq 9 can be numerically integrated to determine the temperature at any position along the liquid jet, $T_{z}$, assuming that $\phi_{\mathrm{e}}$ is known. Raman thermometry measurements of the liquid jet temperature as it evaporates in a vacuum indicate that, for small liquid $\mathrm{H}_{2} \mathrm{O}$ jets $\left(r_{\text {jet }}<5 \mu \mathrm{m}\right), \phi_{\mathrm{e}} \sim 0.35 .{ }^{21}$ For pure $\mathrm{D}_{2} \mathrm{O}, \phi_{\mathrm{e}}$ is somewhat smaller, $\sim 0.25 .^{21}$ The calculated temperature vs distance for liquid jets of different sizes at a constant velocity is shown in Figure 5a.

In the above model of evaporation from a liquid microjet, it is assumed that the characteristic temperature is the bulk liquid temperature and that no temperature gradient exists across the jet (i.e., surface cooling is negligible such that $T_{\text {surf }}=T_{\text {bulk }}$ ). Recently, it was demonstrated that the temperature at the interface of water as it rapidly evaporates is constant to a depth of $\sim 500 \mu \mathrm{m}$, although overall this thick surface layer was cooler than the bulk liquid water reservoir. ${ }^{22}$ It was concluded that thermal mixing due to surface tension driven convection led to the establishment of the observed uniform temperature layer. Given that the liquid jets used in this study are nearly 100 times smaller than the thickness of this constant temperature layer, the assumption made above that the bulk liquid and liquid surface temperatures are equal appears valid. Furthermore, we note that the evaporative cooling model of Maa, ${ }^{11}$ as implemented by Davis et al., ${ }^{23}$ wherein the establishment of a strong temperature gradient between the bulk liquid and surface is explicitly considered for evaporation from very large liquid jets 

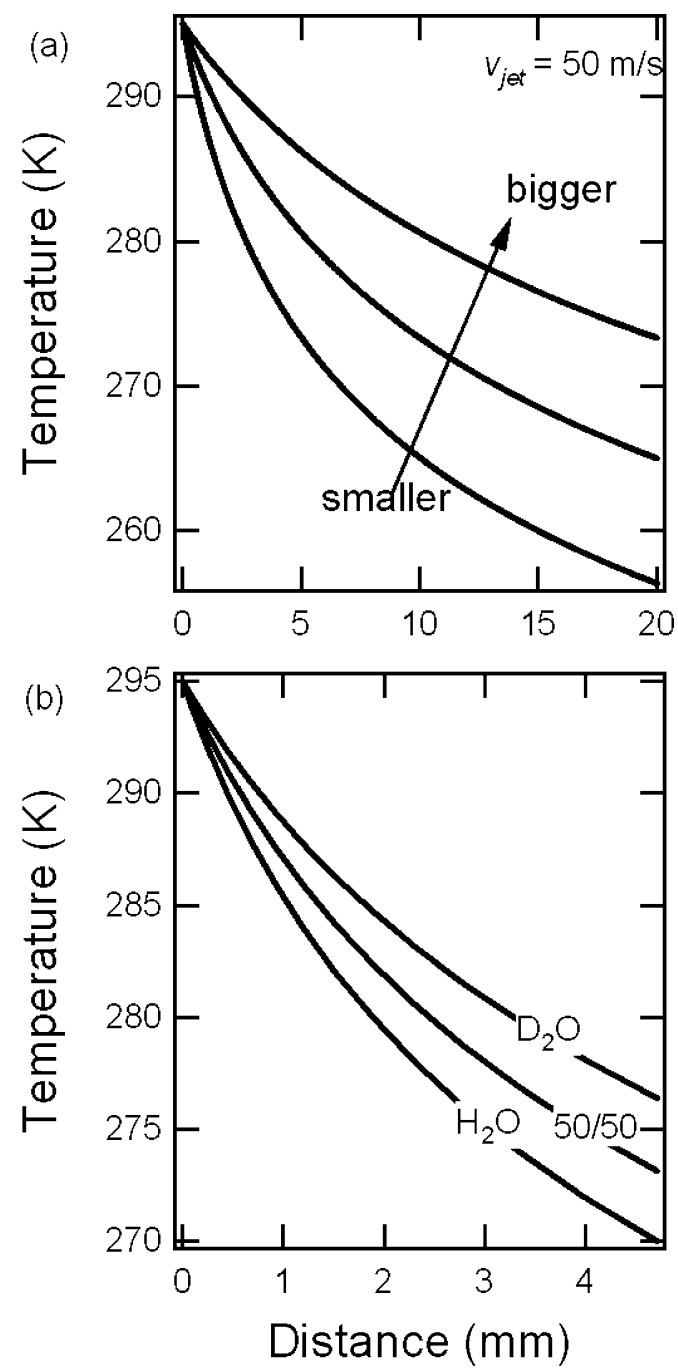

Figure 5. (a) Calculated liquid jet temperature due to evaporative cooling in a vacuum for a pure $\mathrm{H}_{2} \mathrm{O}$ jet with $r_{\mathrm{jet}}=2.5 \mu \mathrm{m}$ (bottom curve), $5 \mu \mathrm{m}$ (middle curve), and $10 \mu \mathrm{m}$ (top curve) at a constant jet velocity of $50 \mathrm{~m} / \mathrm{s}$. (b) Calculated liquid jet temperature for pure $\mathrm{H}_{2} \mathrm{O}$, pure $\mathrm{D}_{2} \mathrm{O}$, and a $50 / 50 \mathrm{H} / \mathrm{D}$ mixture for a $2.5-\mu \mathrm{m}$ liquid jet flowing at $0.04 \mathrm{~mL} / \mathrm{min}(v=34 \mathrm{~m} / \mathrm{s})$. Note the different scales on the $x$-axis for parts $\mathrm{a}$ and $\mathrm{b}$.

$\left(r_{\text {jet }}>100 \mu \mathrm{m}\right)$, fails to describe the experimentally observed liquid jet temperatures from evaporative cooling in a vacuum. The model by Maa actually predicts surface temperatures higher than the experimentally observed average jet temperature measured by Raman spectroscopy ${ }^{21}$ and also that the jet surface temperature is independent of jet size. This result holds even when the theoretical maximum evaporation rate is assumed, indicating that the surface-cooling model is not appropriate for describing evaporation from small liquid jets.

In calculating the jet temperature from the above model for different isotopic solutions, we use the thermodynamic parameters of pure $\mathrm{H}_{2} \mathrm{O}$ and pure $\mathrm{D}_{2} \mathrm{O}$, weighted by the $\mathrm{H}$ or $\mathrm{D}$ mole fraction in solution. It is important to consider the isotopic composition when calculating the jet temperature because the cooling rates for the different solutions (as based on the pure $\mathrm{H}_{2} \mathrm{O}$ and pure $\mathrm{D}_{2} \mathrm{O}$ measurements) are noticeably different (Figure 5b).

2.5. Sizing of Liquid Microjets. To accurately determine the size of small liquid jets, we employ a method wherein the angular variation of the intensity of light elastically scattered by the liquid jet is measured. A HeNe laser $(\lambda=532 \mathrm{~nm})$ is intersected perpendicular to the liquid jet at a distance $\sim 0.5$

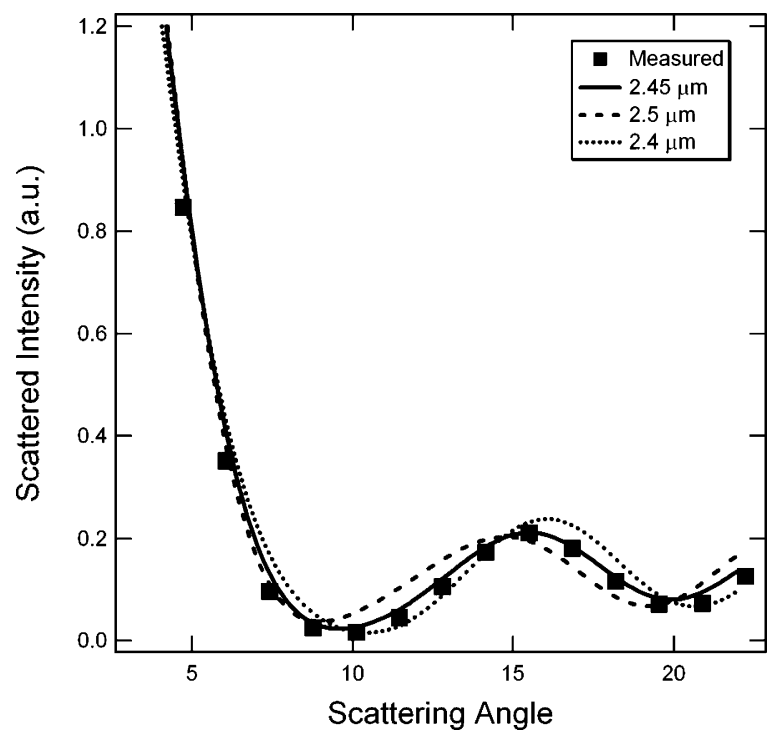

Figure 6. Example of the measured scattered light intensity vs scattering angle used to determine the size of the liquid microjets. The best agreement with theory is found for $r_{\text {jet }}=2.45 \mu \mathrm{m}(-)$. Shown for comparison is the calculated profile for $2.4 \mu \mathrm{m}(\cdots)$ and $2.5 \mu \mathrm{m}(---)$.

$\mathrm{mm}$ from the jet nozzle tip. The intensity of the scattered light is measured on a photodiode located $20 \mathrm{~cm}$ from the liquid jet/ laser interaction region as a function of the scattering angle, $\theta$, from $0^{\circ}$ to $22^{\circ}$. The intensity at a given angle is dependent upon the size of the liquid jet and the real part of the refractive index of the liquid (1.33 for water). As the liquid jet radius is decreased, the number of oscillations observed in the angular window decreases. The observed scattering pattern is matched with that predicted by Mie theory for scattering from a cylinder. ${ }^{24}$ This is shown for a $2.45 \mu$ m radius jet in Figure 6. The liquid microjet radius can be determined to within at least $\pm 0.05 \mu \mathrm{m}$.

\section{Results and Discussion}

The dependence of the isotope ratios $\left(R_{\text {evap }}\right)$ observed in nearly free (ballistic) evaporation from small liquid microjets on the liquid H/D concentration was determined by monitoring the evaporate just as the liquid jet emerged from the nozzle, where the liquid surface temperature is determined to be $T=295_{-5}^{+1}$ K. To compare the $R_{\text {evap }}$ observed at different liquid H/D concentrations, the ratios are referenced to the bulk liquid ratios $\left(R_{\text {liq }}\right)$ and reported as light/heavy $(\mathrm{L} / \mathrm{H})$, e.g., $\mathrm{H}_{2} \mathrm{O} / \mathrm{HDO}$. The evaporation fractionation factor $\left(\alpha_{\text {evap }}\right)$ is defined as $R_{\text {evap }} / R_{\text {liq }}$, analogous to the equilibrium fractionation factor $\left(\alpha_{\text {eqm }}=R_{\text {vapor }}\right.$ ) $R_{\text {liq }}$, where $R_{\text {vapor }}$ is the isotope ratio in the equilibrium vapor). ${ }^{25,26}$ The $R_{\text {liq }}$ values are calculated from the reaction $\mathrm{H}_{2} \mathrm{O}$ $+\mathrm{D}_{2} \mathrm{O} \leftrightarrows \mathrm{HDO}$ using an equilibrium constant of $K_{2}=3.84$. For all isotope ratios, it was observed that $\alpha_{\text {evap }}$ depends strongly on the H/D concentration of the liquid (Figure 7a). At low deuterium mole fractions $\left(\chi_{\mathrm{D}}\right)$, an apparent inverse isotope effect exists, and at high $\chi_{\mathrm{D}}$, the observed fractionations are significantly in excess of the equilibrium values. The observed fractionation between $\mathrm{H}_{2} \mathrm{O}$ and $\mathrm{D}_{2} \mathrm{O}$ is approximately twice as great as that between $\mathrm{H}_{2} \mathrm{O}$ and $\mathrm{HDO}$ or $\mathrm{HDO}$ and $\mathrm{D}_{2} \mathrm{O}$, although this depends explicitly on $\chi_{\mathrm{D}}$.

The value of $\alpha_{\text {evap }}$ from a larger liquid jet ( $r_{\text {jet }}=15 \mu \mathrm{m}$ ) was also measured at $\chi_{\mathrm{D}}=0.825$. For larger jets, a quasi-equilibrium vapor jacket is established around the jet due to the greater number of collisions experienced by evaporating molecules, and recondensation of evaporated molecules consequently becomes 


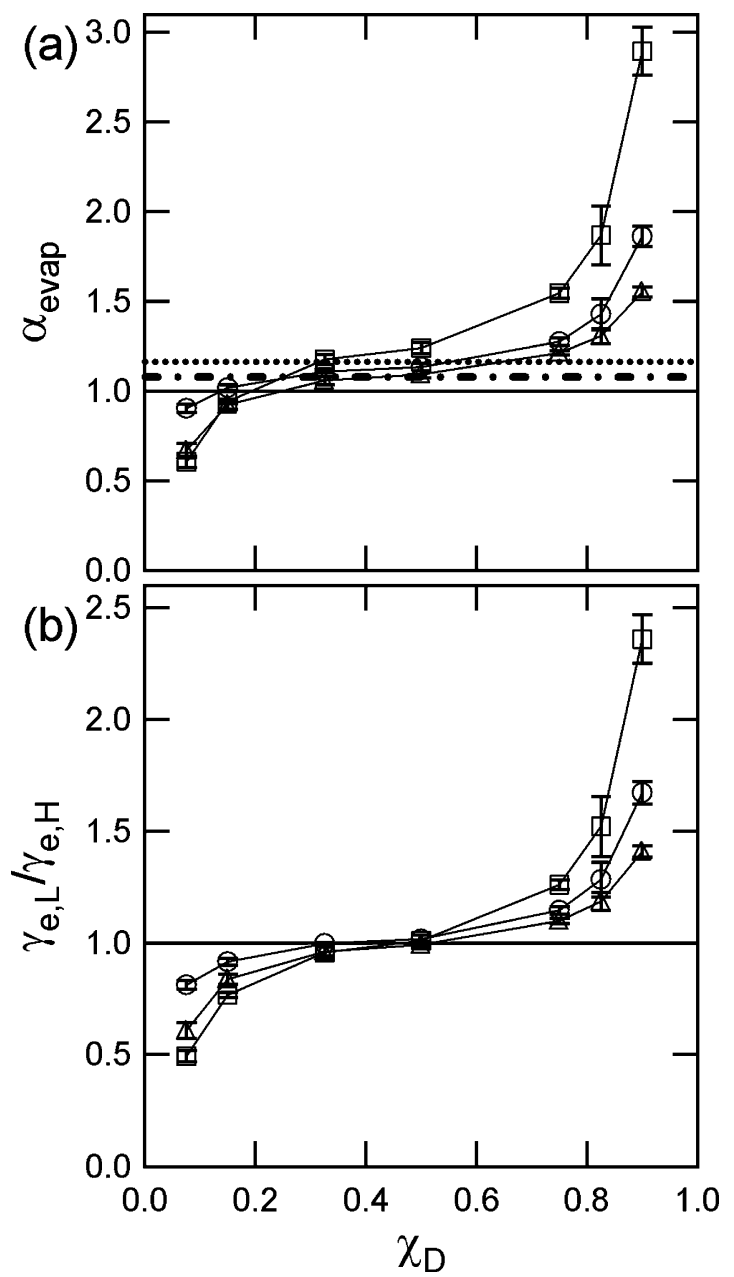

Figure 7. (a) Observed fractionation factors, $\alpha_{\text {evap }}$, associated with free evaporation from a liquid jet for $(O) \mathrm{H}_{2} \mathrm{O} / \mathrm{HDO}$, ( $\left.\square\right) \mathrm{H}_{2} \mathrm{O} / \mathrm{D}_{2} \mathrm{O}$, and $(\triangle) \mathrm{HDO} / \mathrm{D}_{2} \mathrm{O}$ fractionation as a function of liquid deuterium mole fraction ( $2 \sigma$ standard deviations). Values of $\alpha_{\text {eqm }}$ are indicated by the

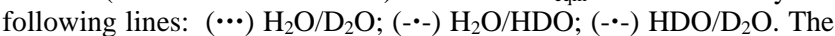
strong composition dependence of $\alpha_{\text {evap }}$ demonstrates that $\gamma_{\mathrm{e}}$ for water is less than unity. (b) Ratio of $\gamma_{\mathrm{e}, \mathrm{L}} / \gamma_{\mathrm{e}, \mathrm{H}}$ calculated from the data in part a and eq 10.

important. Therefore, values of $\alpha_{\text {evap }}$ are expected to approach the equilibrium vapor values as the jet radius is increased. Indeed, $\alpha_{\text {evap }}$ was observed to evolve toward equilibrium fractionation as $r_{\text {jet }}$ was increased from $<3$ to $15 \mu \mathrm{m}$, decreasing from $1.43 \pm 0.08$ to $1.29 \pm 0.02$ for $\alpha_{\text {evap }}\left(\mathrm{H}_{2} \mathrm{O} / \mathrm{HDO}\right)$, from $1.87 \pm 0.16$ to $1.60 \pm 0.04$ for $\alpha_{\text {evap }}\left(\mathrm{H}_{2} \mathrm{O} / \mathrm{D}_{2} \mathrm{O}\right)$, and from 1.31 \pm 0.04 to $1.24 \pm 0.02$ for $\alpha_{\text {evap }}\left(\mathrm{HDO} / \mathrm{D}_{2} \mathrm{O}\right)$ at $295 \mathrm{~K}$ ( $2 \sigma$ errors $)$. For reference, $\alpha_{\text {eqm }}$ is $1.083\left(\mathrm{H}_{2} \mathrm{O} / \mathrm{HDO}\right),{ }^{25} 1.164\left(\mathrm{H}_{2} \mathrm{O} / \mathrm{D}_{2} \mathrm{O}\right),{ }^{26}$ and $1.075\left(\mathrm{HDO} / \mathrm{D}_{2} \mathrm{O}\right)$ at $295 \mathrm{~K}$ and has a negligible dependence on $\chi_{\mathrm{D}}$, in contrast to $\alpha_{\text {evap. }}{ }^{27-30}$

Equilibrium isotope fractionation is a well-characterized phenomenon that describes the generally larger vapor pressure of an isotopically light species compared to that of the heavy isotopomer relative to the corresponding condensed phase composition. ${ }^{31,32}$ The value of $\alpha_{\text {eqm }}$ for pure water shows no significant dependence on isotope composition. ${ }^{27-30}$ Fractionation arises from the different water isotopomers having different zero point energies for their vibrational, librational, and hindered translational motions. At equilibrium, the microscopic rate of transport of water molecules across the liquid surface must be zero (i.e., no net evaporation or condensation). For an isotopic solution, this must hold true individually for each isotopic species. Following from eq 2, the microscopic transport rate for each isotopomer will depend explicitly on $\gamma_{\mathrm{e}}$ and $\gamma_{\mathrm{c}}$. However, because there is no net evaporation or condensation at equilibrium, $\gamma_{\mathrm{e}}$ and $\gamma_{\mathrm{c}}$ play no role in determining the thermodynamic equilibrium property, $\alpha_{\mathrm{eqm}}$. Given the definition of the evaporation and condensation fluxes, it is required that $\gamma_{\mathrm{e}}=\gamma_{\mathrm{c}}$ for each isotopomer at equilibrium.

As a system moves away from equilibrium, evaporation and condensation become unbalanced, and the absolute value of $\gamma_{\mathrm{e}}$ will begin to control the isotope fractionation. For the limiting situation of unidirectional, molecular evaporation (i.e., no recondensation), the fractionation will be driven to a large extent by differences in $\gamma_{\mathrm{e}}$ between the different isotopomers. Only if $\gamma_{\mathrm{e}}=1$ or if $\gamma_{\mathrm{e}, \mathrm{L}}=\gamma_{\mathrm{e}, \mathrm{H}}$ will the observed fractionation factor for pure evaporation be independent of the liquid isotopic composition. If $\alpha_{\text {evap }}$ varies with $\chi_{\mathrm{D}}$, then $\gamma_{\mathrm{e}, \mathrm{L}} \neq \gamma_{\mathrm{e}, \mathrm{H}}$ and $\gamma_{\mathrm{e}}<$ 1. Hence, measurements of the relative evaporation rates of water isotopomers present a direct test of whether $\gamma_{\mathrm{e}}$ is unity. The strong composition dependence of $\alpha_{\mathrm{evap}}$ and the observation that, at most values of $\chi_{\mathrm{D}}, \alpha_{\mathrm{evap}} \neq \alpha_{\mathrm{eqm}}$ provide unambiguous evidence that $\gamma_{\mathrm{e}}<1$. The observed composition dependence indicates that $\gamma_{\mathrm{e}}$ is an explicit function of isotopic composition of the evaporating liquid. We emphasize that because this conclusion is derived from the composition dependence of $\alpha_{\text {evap, }}$, the result is independent of our ability to accurately specify the liquid surface temperature, which has constituted a major uncertainty in previous attempts to determine $\gamma_{\mathrm{e}}$.

From the definitions of $\alpha_{\text {evap }}$ and $\alpha_{\text {eqm }}$ and the Knudsen model of evaporation (eq 1), the ratio of evaporation coefficients between the light and heavy species, $\gamma_{\mathrm{e}, \mathrm{L}} / \gamma_{\mathrm{e}, \mathrm{H}}$, is

$$
\frac{\gamma_{\mathrm{e}, \mathrm{L}}}{\gamma_{\mathrm{e}, \mathrm{H}}}=\left(\frac{m_{\mathrm{L}}}{m_{\mathrm{H}}}\right)^{1 / 2} \frac{R_{\text {evap }}}{R_{\text {eqm }}}=\left(\frac{m_{\mathrm{L}}}{m_{\mathrm{H}}}\right)^{1 / 2} \frac{\alpha_{\text {evap }}}{\alpha_{\text {eqm }}}
$$

In general, $\gamma_{\mathrm{e}, \mathrm{L}} \neq \gamma_{\mathrm{e}, \mathrm{H}}$ and, therefore, $\gamma_{\mathrm{e}}<1$ (Figure 7b). Using the data for $\alpha_{\text {evap }}$ from Figure 7a, if we assume that $\gamma_{\mathrm{e}, \mathrm{H}}$ is a constant, independent of composition, then $\gamma_{\mathrm{e}, \mathrm{L}}$ varies by as much as a factor of 5 , based on the observed $\mathrm{H}_{2} \mathrm{O} / \mathrm{D}_{2} \mathrm{O}$ fractionation. More likely, both $\gamma_{\mathrm{e}, \mathrm{L}}$ and $\gamma_{\mathrm{e}, \mathrm{H}}$ vary with composition in ways that remain to be determined by future theoretical and experimental work. In this scenario, the $\gamma_{\mathrm{e}}$ for $\mathrm{H}_{2} \mathrm{O}$ and $\mathrm{D}_{2} \mathrm{O}$ can vary by as little as a factor of 2 over the concentration range considered. For example, the observed variation in $\gamma_{\mathrm{e}, \mathrm{H}_{2} \mathrm{O}} /$ $\gamma_{\mathrm{e}, \mathrm{D}_{2} \mathrm{O}}$ shown in Figure 7 can be explained if for small $\chi_{\mathrm{D}} \gamma_{\mathrm{e}, \mathrm{H}_{2} \mathrm{O}}$ $=0.20$ and $\gamma_{\mathrm{e}, \mathrm{D}_{2} \mathrm{O}}=0.40$ and for large $\chi_{\mathrm{D}} \gamma_{\mathrm{e}, \mathrm{H}_{2} \mathrm{O}}=0.42$ and $\gamma_{\mathrm{e}, \mathrm{D}_{2} \mathrm{O}}=0.18$.

The strong composition dependence of $\alpha_{\text {evap }}$ is surprising, given that $\alpha_{\text {eqm }}$ shows no measurable dependence on isotope composition. ${ }^{27-30}$ The difference in behavior of $\alpha_{\text {evap }}$ and $\alpha_{\text {eqm }}$ with composition indicates that values of $\gamma_{\mathrm{e}}$ for the different isotopic species exhibit dramatically different sensitivities to changes in intra- and intermolecular frequencies upon condensation and that these frequencies depend explicitly on composition. This suggests that fundamental differences exist between the molecular-scale interactions that determine $\alpha_{\text {eqm }}$ (a thermodynamic property) and $\alpha_{\text {evap }}$ (a kinetic property).

As a liquid jet is injected into a vacuum, the evaporating molecules efficiently transport heat away from the liquid, causing the liquid jet to cool. ${ }^{5}$ Therefore, $\alpha_{\text {evap }}$ can be conveniently measured as a function of temperature by sampling at different positions along the liquid jet axis of propagation. We find that $\alpha_{\text {evap }}$ increases dramatically with decreasing temperature, as shown for a $\chi_{\mathrm{D}}=0.5$ isotopic solution over the temperature range 295-264 K (Figure 8a). This result indicates 


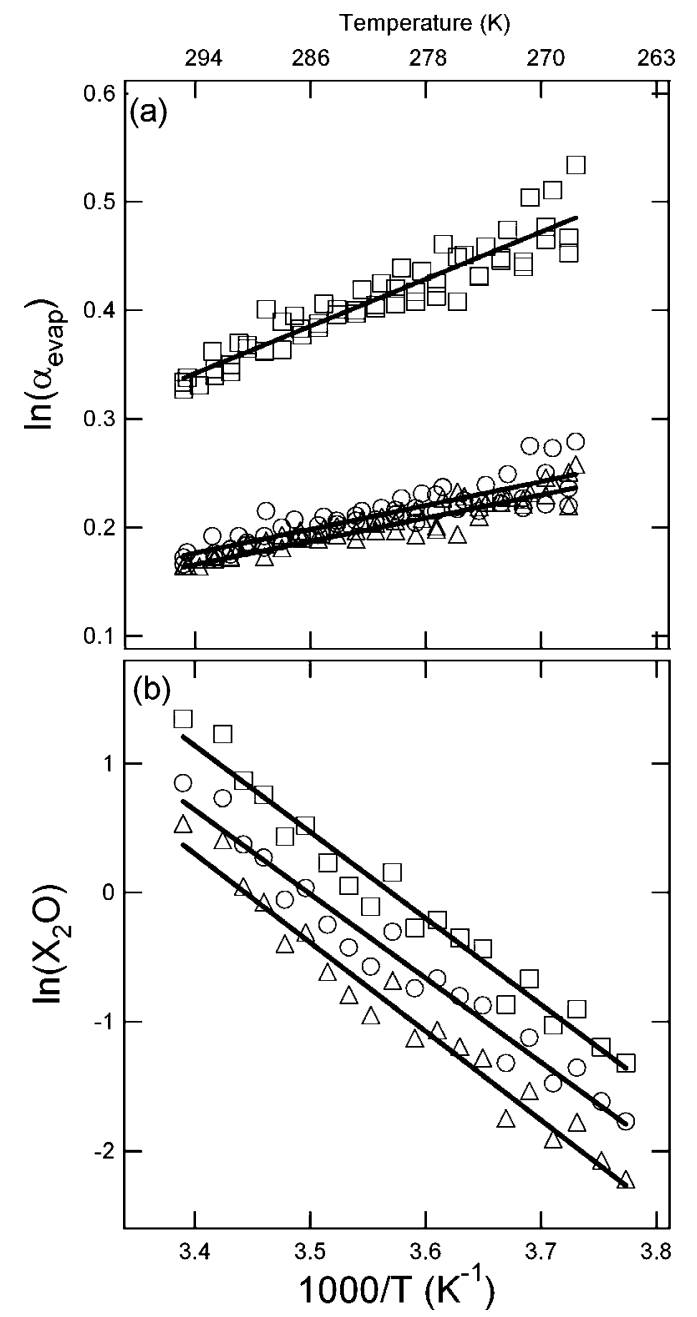

Figure 8. (a) Temperature dependence of the observed evaporation fractionation factors in a $T$ range from 264 to $295 \mathrm{~K}$ from the $\chi_{\mathrm{D}}=0.5$ solution for $(O) \mathrm{H}_{2} \mathrm{O} / \mathrm{HDO}$, $(\square) \mathrm{H}_{2} \mathrm{O} / \mathrm{D}_{2} \mathrm{O}$, and $(\triangle) \mathrm{HDO} / \mathrm{D}_{2} \mathrm{O}$. Using an Arrhenius model for evaporation, a plot of $\ln \left(\alpha_{\text {evap }}\right)$ vs $1 / T$ will have a slope equal to $-\Delta E_{\mathrm{a}} / R$ and an intercept equal to $\ln \left(A_{\mathrm{L}} / A_{\mathrm{H}}\right)$ (see text for details). These results show that $\Delta E_{\mathrm{a}}=-1.8 \pm 0.3,-3.6 \pm 0.4$, and $-1.8 \pm 0.2 \mathrm{~kJ} / \mathrm{mol}$ and $A_{\mathrm{L}} / A_{\mathrm{H}}=0.6 \pm 0.1,0.4 \pm 0.1$, and $0.6 \pm$ 0.1 for $\mathrm{H}_{2} \mathrm{O} / \mathrm{HDO}, \mathrm{H}_{2} \mathrm{O} / \mathrm{D}_{2} \mathrm{O}$, and $\mathrm{HDO} / \mathrm{D}_{2} \mathrm{O}$ fractionation, respectively. (b) Temperature dependence of the absolute desorption rates for $(\mathrm{O})$ $\mathrm{H}_{2} \mathrm{O},(\square) \mathrm{HDO}$, and $(\triangle) \mathrm{D}_{2} \mathrm{O}$ from the $\chi_{\mathrm{D}}=0.5$ solution. The $E_{\mathrm{a}}$ values for evaporation of $\mathrm{H}_{2} \mathrm{O}, \mathrm{HDO}$, and $\mathrm{D}_{2} \mathrm{O}$ are $55 \pm 5,57 \pm 5$, and $58 \pm$ $5 \mathrm{~kJ} / \mathrm{mol}$, respectively.

that the differences between the $\gamma_{\mathrm{e}}$ 's for the different isotopic species depend strongly upon temperature for this $\chi_{\mathrm{D}}=0.5$ solution.

The evaporation of a molecule from a surface can be treated as a first order chemical reaction, dependent only on the surface composition and the rate constant for evaporation with

$$
J_{\mathrm{e}, \mathrm{X}}=\frac{\mathrm{d}[\mathrm{X}]}{\mathrm{d} t}=k_{\text {evap }}[\mathrm{X}]_{\mathrm{surf}}
$$

where $k_{\text {evap }}$ has units of $1 / \mathrm{s}$ and $[\mathrm{X}]_{\text {surf }}$ has units of molecules/ $\mathrm{cm}^{2}$. The relative evaporation rates of the water isotopomers determine the extent of fractionation and, therefore, the observed $R_{\text {evap. Hence, }}$

$$
R_{\text {evap }}=\frac{J_{\mathrm{e}, \mathrm{L}}}{J_{\mathrm{e}, \mathrm{H}}}=\frac{k_{\text {evap }}{ }^{\mathrm{L}}}{k_{\text {evap }}{ }^{\mathrm{H}}} \frac{[\mathrm{L}]_{\text {surf }}}{[\mathrm{H}]_{\text {surf }}}=\frac{A_{\mathrm{L}} \mathrm{e}^{-E_{\mathrm{a}}^{\mathrm{L} / R T}}}{A_{\mathrm{H}} \mathrm{e}^{-E_{\mathrm{a}}^{\mathrm{H} / R T}}} \frac{[\mathrm{L}]_{\text {surf }}}{[\mathrm{H}]_{\text {surf }}}
$$

where we have assumed an Arrhenius form for $k_{\text {evap. If the }}$ isotope ratios at the liquid-vapor interface are equal to the bulk liquid ratios, eq 12 can be reformulated as

$$
\alpha_{\text {evap }}=\frac{R_{\text {evap }}}{R_{\text {liq }}}=\frac{A_{\mathrm{L}}}{A_{\mathrm{H}}} \mathrm{e}^{-\Delta E_{\mathrm{a}} / R T}
$$

where $\Delta E_{\mathrm{a}}=E_{\mathrm{a}}^{\mathrm{L}}-E_{\mathrm{a}}^{\mathrm{H}}$ is the difference in activation energies for evaporation between the isotopomers and $A_{\mathrm{L}} / A_{\mathrm{H}}$ is the ratio of prefactors. For a $\chi_{\mathrm{D}}=0.5$ solution, $\Delta E_{\mathrm{a}}=-1.8 \pm$ $0.3,-3.6 \pm 0.4$, and $-1.8 \pm 0.2 \mathrm{~kJ} / \mathrm{mol}$ and $A_{\mathrm{L}} / A_{\mathrm{H}}=0.6 \pm$ $0.1,0.4 \pm 0.1$, and $0.6 \pm 0.1$ for $\mathrm{H}_{2} \mathrm{O} / \mathrm{HDO}, \mathrm{H}_{2} \mathrm{O} / \mathrm{D}_{2} \mathrm{O}$, and $\mathrm{HDO} / \mathrm{D}_{2} \mathrm{O}$ fractionation, respectively (Figure $8 \mathrm{a}$ ).

The $\Delta E_{\mathrm{a}}$ observed here for $\mathrm{H}_{2} \mathrm{O} / \mathrm{D}_{2} \mathrm{O}$ in the $\chi_{\mathrm{D}}=0.5$ solution is approximately twice the difference in the enthalpy of vaporization of pure liquid $\mathrm{H}_{2} \mathrm{O}$ and $\mathrm{D}_{2} \mathrm{O}\left(\Delta\left(\Delta H_{\text {vap }}\right)=-1.5\right.$ $\mathrm{kJ} / \mathrm{mol})$. In contrast, if $\alpha_{\text {eqm }}\left(\mathrm{H}_{2} \mathrm{O} / \mathrm{D}_{2} \mathrm{O}\right)$ is fit to the Arrhenius model ( $\ln \alpha_{\text {eqm }}$ vs $1 / T$ ) over a similar temperature range, the slope corresponds to $-1.5 \mathrm{~kJ} / \mathrm{mol}$, equal to $\Delta\left(\Delta H_{\mathrm{vap}}\right)$. (We note that if the temperature dependence of $\alpha_{\text {eqm }}$ is considered over a relatively large temperature range, e.g., from the triple point to the critical point, nonnegligible curvature is observed in a plot of $\ln \alpha_{\text {eqm }}$ vs $1 / T$. We might, therefore, expect the linearity of a plot of $\ln \alpha_{\text {evap }}$ vs $1 / T$ to hold only over a similarly restricted temperature range.) Because $\alpha_{\text {eqm }}$ is controlled by both evaporation and condensation, this indicates that an activation energy difference associated with fractionation during free condensation also exists, with $\Delta E_{\mathrm{a}, \mathrm{c}}=2.1 \pm 0.6 \mathrm{~kJ} / \mathrm{mol}$ for $\chi_{\mathrm{D}}=0.5$. Given the observed composition dependence of $\alpha_{\text {evap }}$ and the above interpretation of the physical properties $\left(\Delta E_{\mathrm{a}}\right.$ and $\left.A_{\mathrm{L}} / A_{\mathrm{H}}\right)$ controlling $\alpha_{\text {evap }}$, it is necessary that either $\Delta E_{\mathrm{a}}$ or $A_{\mathrm{L}} / A_{\mathrm{H}}$ vary with composition. Preliminary results suggest that both terms vary with composition.

In the above experiments, we have focused on measuring relative evaporation rates for isotopic water species. However, in the temperature-dependent measurements, the absolute signal levels decrease rapidly as the jet temperature decreases. Accordingly, the activation energy $\left(E_{\mathrm{a}}\right)$ associated with free evaporation of an individual isotopic species can be estimated from the absolute signal decrease with temperature (Figure $8 b$ ). The accuracy and precision of this method in determining $E_{\mathrm{a}}$ is limited by the reproducibility in placing the liquid jet at the exact same on position for every temperature, as well as by the accurate determination of the jet temperature. Small variations in the angle of the jet with respect to the skimmer cause the jet to move closer to or further away from the skimmer, thereby yielding inaccurate signal decays with temperature; we note that the measurement of isotope ratios does not exhibit this same sensitivity to the jet position. Also, the temperature of the mixed isotopic solutions has not been as well constrained as that for the pure liquids has been, and therefore, the evaporative cooling model provides only an estimate of the liquid jet temperature. The Arrhenius prefactor (assumed to be temperature independent) cannot be determined because the absolute evaporation rates have not been measured. Nonetheless, the $E_{\mathrm{a}}$ values we derive for evaporation from a $\chi_{\mathrm{D}}=0.5$ solution are $\sim 10 \mathrm{~kJ} /$ mol greater than the corresponding $\Delta H_{\mathrm{vap}}$ values for the isotopically pure liquids. ${ }^{33}$ Thus, there exists a significant barrier to free evaporation for liquid water that, in part, causes $\gamma_{\mathrm{e}}$ to be less than unity. Correspondingly, this result indicates that there is an activation energy associated with condensation. The $E_{\mathrm{a}}$ observed here for the $\chi_{\mathrm{D}}=0.5$ solution is similar to the $E_{\mathrm{a}}$ derived from absolute desorption rate measurements of pure $\mathrm{H}_{2} \mathrm{O}$ and $\mathrm{D}_{2} \mathrm{O}$ ices ${ }^{17,34}$ but is somewhat higher than those from some other measurements of $E_{\mathrm{a}}$ for ice desorption. ${ }^{35,36}$ This compari- 
son is not meant to suggest that the liquid water jet exhibits icelike properties but simply indicates that the activation energies measured here in excess of $\Delta H_{\text {vap }}$ for evaporation are not unprecedented for systems containing water.

We have estimated the variability in $\gamma_{\mathrm{e}}$ with temperature by calculating the evaporation flux from eq 11 using the observed $E_{\mathrm{a}}$ and comparing to $J_{\mathrm{e}, \max }$. If $J_{\mathrm{e}, \max }$ is fit to the Arrhenius model over a similar temperature range, the slope is approximately equal to $\Delta H_{\text {vap. }}$. Thus, $\gamma_{\mathrm{e}}$ will vary exponentially with $E_{\mathrm{a}}$ according to $\gamma_{\mathrm{e}} \propto \exp \left(-\left(E_{\mathrm{a}}-\Delta H_{\mathrm{vap}}\right) / R T\right)$. The actual value of $\gamma_{\mathrm{e}}$ will be determined by both $E_{\mathrm{a}}$ and the ratio of the prefactors for $J_{\mathrm{e}, \mathrm{obs}}$ and $J_{\mathrm{e}, \max }\left(A_{\mathrm{e}}=A_{\mathrm{e}, \mathrm{obs}} / A_{\mathrm{e}, \max }\right)$. This interpretation of the observations indicates that $\gamma_{\mathrm{e}}$ is temperature dependent, becoming smaller at lower temperatures. For example, $\gamma_{\mathrm{e}}$ at 295 $\mathrm{K}$ is approximately double its value at $255 \mathrm{~K}$ if we assume $E_{\mathrm{a}}$ $=55 \mathrm{~kJ} / \mathrm{mol}$. On the basis of these results, we have developed a transition state theory model of evaporation of liquid water that indicates that $A_{\mathrm{e}}$ is greater than 1 and that $\gamma_{\mathrm{e}}$ is $\sim 0.3$ at $295 \mathrm{~K}^{37}$

Our results are consistent with recent classical molecular dynamics (MD) simulations of water-air and water-liquid interfaces, where it was demonstrated that, although there are fewer hydrogen bonds formed by water molecules at the interface than in the bulk liquid (due to the decreased density), when scaled by the coordination number, the fractional number of hydrogen bonds formed is actually greater. ${ }^{38,39}$ This result indicates that water molecules at the liquid-air interface have a stronger tendency to form hydrogen bonds than do those in the bulk liquid, which may lead to a decreased evaporation rate relative to the theoretical maximum and be responsible for the large observed $E_{\mathrm{a}}$. We note also that velocity distributions of evaporating (and condensing) molecules determined from MD simulation have been found to be non-Maxwellian, suggesting the presence of an energetic barrier to evaporation. ${ }^{40,41}$ Theoretical consideration of the kinetic energy distributions of freely evaporating water molecules also indicates that the velocity distributions of the emitted molecules are non-Maxwellian under some conditions. ${ }^{42,43}$ The results from another MD study of evaporation ${ }^{44}$ indicated that the evaporation coefficient is both less than unity and increases with temperature, as is suggested by our observations, although a separate study ${ }^{45}$ suggests the opposite temperature dependence. In contrast, MD simulations ${ }^{40,46,47}$ have also been used to determine the mass accommodation coefficient for water on water, the results of which indicate that the uptake coefficient of water on water at ca. 300$350 \mathrm{~K}$ is $\sim 1$, inconsistent with the results presented here. We note, however, that the methods used to determine MA from classical MD simulations have recently been questioned. ${ }^{48}$ It is also of interest that the calculated MA decreased with increasing temperature in the one simulation where condensation was considered at much higher temperatures. ${ }^{40}$ Given these varying results, it appears that, at this point, simulations cannot provide definitive values for the evaporation or mass accommodation coefficients.

The fact that $\alpha_{\text {evap }}$ is not equal to $\alpha_{\text {eqm }}$, and is also a strong, nonlinear function of $\chi_{\mathrm{D}}$, allows us to speculate as to the nature of the critical surface species involved in evaporation. The isotopic composition dependence indicates the importance of the first solvation shell in controlling evaporation. Specifically, the nature of acceptor and donor hydrogen bonds, and their influence on librational and hindered translational motions, will determine evaporation rates. Both acceptor and donor hydrogen bonds will be affected by changing the solvent composition, but in different fashions. Acceptor bonds will exhibit a strong direct sensitivity to compositional changes, because they depend explicitly on whether the donated hydrogen bond (from the solvent) contains a hydrogen or deuterium atom (e.g., $\mathrm{O}-\mathrm{H} \cdot$ $\cdot \mathrm{OH}_{2}$ vs $\left.\mathrm{O}-\mathrm{D} \cdots \mathrm{OH}_{2}\right)$. In contrast, the nature of the donor hydrogen bonds (to the solvent) is only indirectly affected by compositional changes (e.g., $\mathrm{H}_{2} \mathrm{O} \cdots \mathrm{H}-\mathrm{O}$ vs $\mathrm{HDO} \cdots \mathrm{H}-\mathrm{O}$ ), although this indirect influence may indeed be important. The strong dependence of $\gamma_{\mathrm{e}}$ on isotope composition suggests that it may be affected strongly by other factors as well, such as the presence of dissolved inorganic salts or organic species that cause changes in the hydrogen bonding network, suggesting interesting directions for future study.

\section{Evaporation vs Mass Accommodation}

It is important to make a clear connection between the results described above for evaporation and the reverse process of condensation. As mentioned in the Introduction, two recent experimental determinations of the mass accommodation coefficient for water vapor onto water gave quite different results. A discussion of the two results has been presented by Davidovits et al. ${ }^{49}$ Measuring the uptake of $\mathrm{H}_{2}{ }^{17} \mathrm{O}$ from the gas phase into a water droplet train at near equilibrium conditions, $\mathrm{Li}$ et al. determined that MA is less than unity and exhibits a negative temperature dependence, ranging from 0.17 (at $280 \mathrm{~K}$ ) to 0.32 (at $253 \mathrm{~K}) \cdot{ }^{12}$ In contrast, Winkler et al. determined that MA = 1 based on the measurement of condensation rates of water onto silver particles in air at supersaturations of $1.3-1.45 .{ }^{13}$ It has been suggested that the discrepancy between these two experiments might arise because the high supersaturations and rapid droplet growth in the Winkler et al. experiments engenders a physical situation wherein "surface accommodation of water vapor molecules might be followed by very efficient mass accommodation as the newly arriving flux promotes their incorporation into the bulk liquid." ${ }^{49}$ However, we note also that the results of $\mathrm{Li}$ et al. have recently been called into question by fluid dynamics simulations of the droplet train apparatus that propose that the uncertainty in MA is so large that the possibility of MA being equal to 1 cannot be ruled out. ${ }^{46}$ Noting this debate, we will nevertheless limit the comparison between $\gamma_{\mathrm{e}}$ and MA to the results of $\mathrm{Li}$ et al. (referred to henceforth as the Boston College/Aerodyne collaboration, or BCA $)^{12}$ because our experiments suggest that $\gamma_{\mathrm{e}}<1$. We begin by considering the formulation of mass accommodation given by BCA (see, e.g., Kolb et al. ${ }^{15}$ for a thorough discussion). In the droplet train experiments of BCA, the uptake of a gas onto water is considered as a net process, wherein re-evaporation of molecules trapped temporarily at the surface and of those that have fully accommodated must be explicitly considered. The BCA experiments formulate uptake in terms of a resistance model, with the observed uptake, $\gamma_{\text {obs }}$, expressed as

$$
\frac{1}{\gamma_{\mathrm{obs}}}=\frac{1}{\Gamma_{\mathrm{diff}}}+\frac{1}{\Gamma_{\mathrm{sol}}}+\frac{1}{\mathrm{MA}}
$$

where $\Gamma_{\text {diff }}$ is the diffusive gas-phase transport resistance, $\Gamma_{\text {sol }}$ is the Henry's law solubility resistance, and MA is the mass accommodation coefficient as defined by the BCA experiment. In the molecular evaporation experiments presented here, there is no analogue to $\Gamma_{\text {diff. }}$ The effects associated with $\Gamma_{\text {sol }}$ have some parallel to the diffusive limitations to formation of a surface species. However, for a saturated solution such as that which was used in our liquid jet experiments, we expect this effect to be negligible. Assuming that thermal accommodation is efficient (i.e., no molecules incident on the surface are directly 
scattered away), the mass accommodation process can be written so as to depend only on the relative rates of surface desorption (process 2 in Figure 1a) and bulk liquid solvation (process 3 in Figure 1a). This can be represented as ${ }^{14,15}$

$$
n_{\mathrm{g}} \underset{k_{2}}{\stackrel{k_{4}}{\rightleftarrows}} n_{\mathrm{s}} \stackrel{k_{3}}{\longrightarrow} n_{1}
$$

Here, the subscripts g, s, and 1 refer to the gas phase, surface species, and liquid phase, respectively. The subscript numbers refer to the processes represented in Figure 1a. From this, the temperature dependence of MA is given by

$$
\frac{\mathrm{MA}}{1-\mathrm{MA}}=\frac{k_{3}}{k_{2}}=\exp \left(\frac{-\Delta G_{\mathrm{BCA}}}{R T}\right)
$$

where $\Delta G_{\mathrm{BCA}}=\Delta H_{\mathrm{BCA}}-T \Delta S_{\mathrm{BCA}}$ is the free energy difference between the gas phase and surface transition state. In eq 15 , there is no consideration of the transfer of completely solvated molecules to the surface (i.e., process 1) because this is taken as a separable property that is treated by the consideration of the Henry's law solubility of the gas, as given in eq 14; evaporation is, therefore, treated as a separate phenomenon from the uptake process. This solubility limit leads to a decrease in the observed uptake with time as the liquid becomes saturated with respect to the trace gas concentration.

Applying the same logic to the evaluation of evaporation from the liquid jet, we find that only the processes represented by eq 17 are relevant, namely

$$
n_{\mathrm{g}} \stackrel{k_{2}}{\longleftarrow} n_{\mathrm{s}} \underset{k_{1}}{\stackrel{k_{3}}{\rightleftarrows}} n_{1}
$$

and that the evaporation flux can then be expressed as

$$
J_{\mathrm{e}}=n_{\mathrm{s}} k_{2}
$$

or as

$$
J_{\mathrm{e}}=n_{\mathrm{l}} k_{1}-n_{\mathrm{s}} k_{3}
$$

In eq 18 , the evaporation rate is the rate of transfer of molecules from the surface to the gas phase, whereas in eq 19 the evaporation rate is the difference between the rates of transfer to the surface from the bulk liquid and vice versa. Using these two relationships,

$$
n_{\mathrm{s}}=\frac{n_{1} k_{1}}{k_{2}+k_{3}}
$$

and therefore,

$$
J_{\mathrm{e}}=n_{1} \frac{k_{2} k_{1}}{k_{2}+k_{3}}=n_{1}\left[\frac{k_{2}+k_{3}}{k_{2} k_{1}}\right]^{-1}=n_{1}\left[\frac{1}{k_{1}}+\frac{1}{k_{1}} \frac{k_{3}}{k_{2}}\right]^{-1}
$$

Recognizing the ratio $k_{3} / k_{2}$ from eq 16 in the BCA formulation, we can rewrite $J_{\mathrm{e}}$ in terms of $\Delta G_{\mathrm{BCA}}$ as

$$
J_{\mathrm{e}}=n_{1}\left[\frac{1}{k_{1}}+\frac{1}{k_{1}} \mathrm{e}^{\Delta G_{\mathrm{BCA}} / R T}\right]^{-1}=n_{1}\left[\frac{1}{k_{1}}+\frac{1}{k_{1}} \frac{\mathrm{MA}}{1-\mathrm{MA}}\right]^{-1}
$$

which simplifies to

$$
J_{\mathrm{e}}=n_{1} k_{1}(1-\mathrm{MA})
$$

Here, $n_{1}$ is the liquid-phase concentration and $k_{1}$ is in $\mathrm{m} / \mathrm{s}$. From the definition of $\gamma_{\mathrm{e}}$ given in eq 2 , we find the relationship between $\gamma_{\mathrm{e}}$ and MA

$$
\gamma_{\mathrm{e}}=\frac{n_{1} k_{1}(1-\mathrm{MA})}{J_{\mathrm{e}, \max }}
$$

We find that $\gamma_{\mathrm{e}}$ and MA are not equivalent but that $\gamma_{\mathrm{e}} \propto(1$ - MA). This reflects the idea that if surface molecules are returned to the bulk liquid much faster than they desorb/ evaporate from the surface (i.e., $k_{3} \gg k_{2}$ ) then a negligible number of molecules will actually evaporate. In the limiting case where $\mathrm{MA} \rightarrow 1, \gamma_{\mathrm{e}} \rightarrow 0$ and no molecules will evaporate. In the BCA formulation of mass accommodation (eq 16), a value of $\mathrm{MA}=1$ is not allowed, although MA asymptotically approaches unity as the temperature is decreased. If we assume $k_{1}$ is temperature independent, $\gamma_{\mathrm{e}}$ and MA are expected to exhibit the opposite temperature dependence, as is suggested by our measurements of evaporation and the BCA experiments on uptake. ${ }^{12}$ Although the apparent definitions of MA and $\gamma_{\mathrm{e}}$ are the same (cf. eq 2), this indicates that the uptake experiments probe the mass transfer process in a fundamentally different way than the free evaporation experiments, as is clear from consideration of the processes represented in eqs 15 and 17.

This difference arises because evaporation, as expressed in eq 17 , effectively defines a dividing surface between the vapor phase and liquid surface over which molecules must cross to be counted as "evaporated". In contrast, mass accommodation is expressed in terms of the transport of molecules across a dividing surface located between the liquid surface and the bulk liquid in the BCA formulation (see Figure 1b). This distinction is important because, in the BCA experiments, any molecules that are "lost" to the surface on the time scale of the experiment will be counted as accommodated even if they have not crossed the dividing surface defined by the uptake model.

\section{Atmospheric Implications}

The kinetics of evaporation and condensation plays a crucial role in determining the formation rates and lifetimes of clouds and aerosols in the atmosphere by affecting the rates of loss from and uptake onto preexisting particles. ${ }^{50-52}$ In particular, it has been shown that droplet growth is highly sensitive to variations in MA if MA $<\sim 0.1$ but is relatively insensitive to variations in MA for larger values, wherein droplet growth becomes diffusion limited. ${ }^{51,52}$ Although there is no consensus as to the exact magnitude of MA (perhaps as a result of differing experimental definitions), it is generally agreed that for pure water at ambient temperatures MA $>0.1,7,49$ and, therefore, is not expected to limit cloud growth. However, in most cloud growth models it is assumed that the "condensation" coefficient and the evaporation coefficient are equal and that the condensation coefficient is equivalent to the mass accommodation coefficient. Our analysis indicates that careful consideration of how to best define the mass transfer coefficients associated with cloud formation and evaporation is necessary, although beyond the scope of the present work.

If the kinetic limitation on cloud dynamics imposed by having $\gamma_{\mathrm{e}}<1$ is significant, cloud droplet nuclei will not be as efficiently activated and the resulting droplet size distribution will be affected. ${ }^{50}$ Although we have not directly measured the evaporation coefficient in these experiments, variations in $\gamma_{\mathrm{e}}$ with temperature could be important in cloud formation processes, because, unlike the mass accommodation coefficient, ${ }^{12} \gamma_{\mathrm{e}}$ is expected to decrease with temperature. In clean atmospheres, liquid water has been known to persist to approximately $-40{ }^{\circ} \mathrm{C}(233 \mathrm{~K})$, where we predict $\gamma_{\mathrm{e}}$ will decrease by more than a factor of 3 compared to $\gamma_{\mathrm{e}}$ at $295 \mathrm{~K}$. Thus, it is 
possible that at low temperatures $\gamma_{\mathrm{e}}<0.1$, and it is, therefore, conceivable that differences in cloud formation properties exist at different latitudes and altitudes.

Additionally, our experiments have also demonstrated the extreme sensitivity of $\gamma_{\mathrm{e}}$ to composition, even for liquid water solutions of varying isotopic composition. Because supersaturations of several hundred percent are necessary to engender the homogeneous nucleation of water droplets in clean air, most clouds are formed on preexisting cloud condensation nuclei (CCN), which are often composed of somewhat soluble inorganic ions and organic material. ${ }^{52}$ Our results suggest that the presence of these ions or other soluble or insoluble material in cloud droplets is likely to have a dramatic effect on the evaporation coefficient and mass accommodation coefficient for water. It is well-recognized that the presence of dissolved ions decreases the equilibrium vapor pressure over liquid water; in the case of clouds, this is particularly important for very small droplets. ${ }^{52}$ However, the effect of ions on the kinetic mass transfer coefficients has not been explicitly considered. Additionally, soft anions have different propensities to exist at the liquid water surface, ${ }^{53,54}$ and therefore, the effect of solutes on $\gamma_{\mathrm{e}}$ may be highly solute dependent. As such, clouds that are formed in different regions of the earth may form with $\gamma_{\mathrm{e}}$ values characteristic of the particular CCN composition. The CCN concentration in a particular region is often estimated as $N_{\mathrm{c}}=C S^{k}$, where $S$ is the supersaturation and $C$ and $k$ are empirically determined parameters dependent on the size and composition of the aerosol population. ${ }^{55}$ It is possible that observed differences in the empirical $C$ and $k$ values in different locations may be, in part, determined by the variability of $\gamma_{\mathrm{e}}$ between different air masses or regions.

\section{Conclusions}

Our measurements of the isotope fractionation factors associated with the free evaporation of liquid water unambiguously demonstrate that the evaporation coefficient of water is less than unity. This is primarily evidenced by the unique dependence of $\alpha_{\text {evap }}$ on the isotopic composition of the liquid. Additionally, the measured temperature dependence of $\alpha_{\text {evap }}$ differs from that of the equilibrium fractionation factor. The dependence of $\alpha_{\text {evap }}$ on $\chi_{\mathrm{D}}$ indicates that evaporation depends strongly on both the identity of the evaporating molecule and the nature of the first solvation shell. The temperature dependence of the evaporation rates for the individual isotopic signals indicates that an energetic barrier to evaporation exists and, consequently, that the evaporation coefficient decreases with temperature.

Acknowledgment. This research was supported by the National Science Foundation Atmospheric Chemistry Program under Grant No. ATM-0138669 (R.C.C.) and the Chemical Sciences, Geosciences and Biosciences Division, Office of Basic Energy Sciences, U.S. Department of Energy (R.J.S.). C.D.C. was supported by the Advanced Light Source Doctoral Fellowship in Residence and the National Defense Science and Engineering Graduate Fellowship. We thank Dr. Kevin R. Wilson for early experimental assistance.

\section{References and Notes}

(1) Charlson, R. J.; Schwartz, S. E.; Hales, J. M.; Cess, R. D.; Coakley, J. A.; Hansen, J. E.; Hofmann, D. J. Science 1992, 255, 423.

(2) Nenes, A.; Ghan, S.; Abdul-Razzak, H.; Chuang, P. Y.; Seinfeld, J. H. Tellus 2001, 53B, 133 .

(3) Nathanson, G. M. Annu. Rev. Phys. Chem. 2004, 55, 231.

(4) Faubel, M.; Kisters, T. Nature 1989, 339, 527.

(5) Faubel, M.; Schlemmer, S.; Toennies, J. P. Z. Phys. D 1988, 10 , 269.

(6) Eames, I. W.; Marr, N. J.; Sabir, H. Int. J. Heat Mass Transfer 1997, 40, 2963.
(7) Marek, R.; Straub, J. Int. J. Heat Mass Transfer 2001, 44, 39.

(8) Davidovits, P.; Hu, J. H.; Worsnop, D. R.; Zahniser, M. S.; Kolb, C. E. Faraday Discuss. 1995, 65.

(9) Hertz, H. Ann. Phys. 1882, 17, 177.

(10) Hickman, K. C. D. Ind. Eng. Chem. 1954, 46, 1442.

(11) Maa, J. R. Ind. Eng. Chem. Fundam. 1967, 6, 504.

(12) Li, Y. Q.; Davidovits, P.; Shi, Q.; Jayne, J. T.; Kolb, C. E.; Worsnop, D. R. J. Phys. Chem. A 2001, 105, 10627.

(13) Winkler, P. M.; Vrtala, A.; Wagner, P. E.; Kulmala, M.; Lehtinen, K. E. J.; Vesala, T. Phys. Rev. Lett. 2004, 93.

(14) Nathanson, G. M.; Davidovits, P.; Worsnop, D. R.; Kolb, C. E. J. Phys. Chem. 1996, 100, 13007.

(15) Kolb, C. E.; Davidovits, P.; Jayne, J. T.; Shi, Q.; Worsnop, D. R. Prog. React. Kinet. Mech. 2002, $27,1$.

(16) Straub, H. C.; Lindsay, B. G.; Smith, K. A.; Stebbings, R. F. J. Chem. Phys. 1998, 108, 109.

(17) Sadtchenko, V.; Brindza, M.; Chonde, M.; Palmore, B.; Eom, R. J. Chem. Phys. 2004, 121, 11980.

(18) Hirschfelder, J. O. Molecular theory of gases and liquids; J. Wiley: New York, 1954.

(19) Pauly, H. Atomic and molecular beam methods. In Atomic and molecular beam methods; Scoles, G., Ed.; Oxford University Press: New York, 1988; Vol. 1, p 88

(20) The term $\phi_{\mathrm{e}}$ is directly related to $\gamma_{\mathrm{e}}$. However, $\phi_{\mathrm{e}}$ depends specifically on the geometry of the liquid jet and how it breaks up into droplets. Therefore, we use $\phi_{\mathrm{e}}$ in an empirical way to determine the liquid jet temperature without providing a strict physical interpretation at this point.

(21) Smith, J. D.; Cappa, C. D.; Drisdell, W.; Saykally, R. J.; Cohen, R. C. Unpublished data.

(22) Ward, C. A.; Stanga, D. Phys. Rev. E 2001, 6405, 1509.

(23) Davis, E. J.; Chang, R.; Pethica, B. D. Ind. Eng. Chem. Fundam. 1975, 14, 27

(24) Bohren, C. F.; Huffman, D. R. Absorption and scattering of light by small particles; Wiley: New York, 1983.

(25) Horita, J.; Wesolowski, D. J. Geochim. Cosmochim. Acta 1994, 58,3425 .

(26) Kiss, I.; Jakli, G.; Illy, H. Acta Chim. Acad. Sci. Hung. 1966, 47, 379.

(27) Combs, R. L.; Googin, J. M.; Smith, H. A. J. Phys. Chem. 1954, 58,1000 .

(28) Jancso, G.; Jakli, G. Aust. J. Chem. 1980, 33, 2357.

(29) Van Hook, W. A. J. Phys. Chem. 1972, 76, 3040.

(30) Rolston, J. H.; Gale, K. L. J. Phys. Chem. 1982, 86, 2494.

(31) Bigeleisen, J. J. Chem. Phys. 1961, 34, 1485.

(32) Van Hook, W. A. J. Phys. Chem. 1968, 72, 1234

(33) Eisenberg, D. S.; Kauzmann, W. The structure and properties of water; Clarendon Press: Oxford, 1969

(34) Smith, J. A.; Livingston, F. E.; George, S. M. J. Phys. Chem. B 2003, 107, 3871

(35) Haynes, D. R.; Tro, N. J.; George, S. M. J. Phys. Chem. 1992, 96 , 8502 .

(36) Speedy, R. J.; Debenedetti, P. G.; Smith, R. S.; Huang, C.; Kay, B. D. J. Chem. Phys. 1996, 105, 240.

(37) Cappa, C. D. Water Isotopes, Clouds and Aqueous Solutions. Ph.D. Thesis, University of California, Berkeley, CA, 2005.

(38) Benjamin, I. Annu. Rev. Phys. Chem. 1997, 48, 407.

(39) Liu, P.; Harder, E.; Berne, B. J. J. Phys. Chem. B 2005, 109, 2949

(40) Tsuruta, T.; Nagayama, G. J. Phys. Chem. B 2004, 108, 1736.

(41) Tsuruta, T.; Nagayama, G. Energy 2005, 30, 795.

(42) Knox, C. J. H.; Phillips, L. F. J. Phys. Chem. B 1998, 102, 10515

(43) Phillips, L. F. Chem. Phys. Lett. 1997, 266, 161.

(44) Yang, T. H.; Pan, C. Int. J. Heat Mass Transfer 2005, 48, 3516.

(45) Ishiyama, T.; Yano, T.; Fujikawa, S. Phys. Fluids 2004, 16, 4713

(46) Morita, A.; Sugiyama, M.; Kameda, H.; Koda, S.; Hanson, D. R. J. Phys. Chem. B 2004, 108, 9111.

(47) Vieceli, J.; Roeselova, M.; Tobias, D. J. Chem. Phys. Lett. 2004, 393, 249.

(48) Davidovits, P.; Worsnop, D. R.; Williams, L. R.; Kolb, C. E.; Gershenzon, M. J. Phys. Chem. B 2005, 109, 14742.

(49) Davidovits, P.; Worsnop, D. R.; Jayne, J. T.; Kolb, C. E.; Winkler, P.; Vrtala, A.; Wagner, P. E.; Kulmala, M.; Lehtinen, K. E. J.; Vesala, T.; Mozurkewich, M. Geophys. Res. Lett. 2004, 31.

(50) Chuang, P. Y.; Charlson, R. J.; Seinfeld, J. H. Nature 1997, 390 , 594.

(51) Fukuta, N.; Walter, L. A. J. Atmos. Sci. 1970, 27, 1160.

(52) Seinfeld, J. H.; Pandis, S. N. Atmospheric chemistry and physics: from air pollution to climate change; Wiley: New York, 1998.

(53) Jungwirth, P.; Tobias, D. J. J. Phys. Chem. B 2002, 106, 6361.

(54) Vrbka, L.; Mucha, M.; Minofar, B.; Jungwirth, P.; Brown, E. C.; Tobias, D. J. Curr. Opin. Colloid Interface Sci. 2004, 9, 67.

(55) Hobbs, P. V. Aerosol-cloud-climate interactions; Academic Press: San Diego, CA, 1993. 